\title{
Analisis Standar Perancangan Geometri Rel Kereta Cepat (Studi Kasus : Kereta Cepat Jakarta - Bandung)
}

\author{
Analysis of High Speed Railway Geometric Design Standard \\ (Case Study: Jakarta - Bandung High Speed Railway)
}

\author{
Rahmi Fajriati $^{1, \mathrm{a})}$, Suryo Hapsoro Tri Utomo ${ }^{2, \mathrm{~b})}$, Imam Muthohar ${ }^{2, \mathrm{c})}$ \\ ${ }^{1)}$ Mahasiswa S2 Sistem dan Teknik Transportasi, Universitas Gadjah Mada, Yogyakarta \\ ${ }^{2)}$ Departemen Teknik Sipil, Universitas Gadjah Mada, Yogyakarta \\ Koresponden : ${ }^{\text {a) }}$ rahmifajriati@gmail.com, ${ }^{\text {b) }}$ s_hapsoro@yahoo.com \\ c)imam.muthohar@ugm.ac.id
}

\begin{abstract}
ABSTRAK
Saat ini Indonesia sedang dalam tahap pembangunan transportasi masal kereta cepat untuk rute Jakarta - Bandung. Pembangunan kereta cepat dilakukan bekerjasama dengan pihak China. Hal ini membuat hampir seluruh proses perencanaan menggunakan standar perencanaan kereta cepat China. Peraturan Menteri No. 69 Tahun 2019 mengenai Spesifikasi Perencanaan Kereta Berkecepatan Tinggi belum mengatur secara detail mengenai perencanaan geometri kereta cepat di Indonesia. Penelitian ini bertujuan menganalisis perencanaan geometri kereta cepat CR400AF Fuxing Train sehingga dapat dijadikan acuan untuk rekomendasi peraturan perencanaan geometri kereta cepat di Indonesia. Dengan menggunakan metode studi literatur serta pengumpulan data karakteristik kereta CR400AF Fuxing Train, didapatkan jari-jari lengkung minimum sebesar $7080 \mathrm{~m}$, serta peninggian rel yang dibagi menjadi tiga yaitu, peninggian rel minimum 78,3 $\mathrm{mm}$, peninggian rel normal $105,09 \mathrm{~mm}$, dan peninggian rel maksimum $150 \mathrm{~mm}$. Hasil analisis tersebut memenuhi standar perencanaan kereta cepat yang digunakan oleh China. Kemudian persamaan yang digunakan untuk menganalisis direkomendasikan sebagai acuan untuk perencanaan geometri kereta cepat, yaitu menggunakan persamaan dimana gaya sentrifugal yang diimbangi sepenuhnya oleh gaya berat. Selanjutnya, persamaan untuk menghitung peninggian rel menggunakan rumus yang telah umum digunakan namun dimodifikasi sesuai dengan spesifikasi perencanaan kereta cepat Jakarta-Bandung.
\end{abstract}

Kata Kunci : Manajemen Insfrastruktur, High Speed Railway, Jari-jari Lengkung Horizontal, Peninggian Rel, CR400AF Fuxing Train.

\section{PENDAHULUAN}

Saat ini moda transportasi kereta api telah berkembang pesat di Indonesia, tidak hanya dalam penambahan jumlah armada ataupun rute tetapi juga dalam inovasi teknologi konstruksi yang memungkinkan kereta dapat melaju dengan kecepatan tinggi. Salah satu inovasi teknologi konstruksi pendukung kereta cepat adalah dengan menggunakan slab track atau non ballasted track. Banyak pembangunan jalan rel yang telah menggunakan slab track baik itu pada kondisi elevated maupun underground. Jalur kereta yang telah menggunakan teknologi konstruksi ini diantaranya adalah LRT (Light Rail Transit) dan MRT (Mass Rapid Transit). LRT adalah moda transportasi berbasis rel yang mengangkut penumpang dengan massa ringan. LRT hanya melayani rute perkotaan dengan kecepatan masksimum $85 \mathrm{~km} / \mathrm{jam}$. Berbeda dengan MRT, moda transportasi ini mampu mengangkut penumpang dalam jumlah yang lebih besar, interval 
transit yang pendek dan kecepatan yang lebih tinggi yaitu maksimum kecepatan $100 \mathrm{~km} / \mathrm{jam}$. Kedua inovasi kereta yang telah dimiliki hanya melayani rute perkotaan (urban dan interurban). Hal ini menginspirasi pemerintah untuk memiliki kereta cepat yang dapat melayani penumpang jarak jauh.

Tahun 2008, Bappenas bersama Kementerian Perhubungan telah merencanakan pembangunan kereta cepat yang dapat melayani penumpang dari Jakarta menuju Surabaya. Namun akibat terkendala dana dan hal lainnya, rencana tersebut mengalami perubahan yaitu rute yang berubah menjadi Jakarta menuju Bandung. Saat ini kereta cepat Jakarta-Bandung atau disebeut juga dengan High Speed Railway Jakarta-Bandung (HSRJB) sedang dalam proses pembangunan. Kereta cepat ini diperkirakan akan melaju dengan kecepatan maksimum 350 $\mathrm{km} / \mathrm{jam}$ atau hampir 3,5 kali lebih cepat dibandingkan dengan kereta yang ada di Indonesia. Bapak Menteri Perhubungan, Budi Karya Sumadi, telah menandatangai kesepakatan bersama tentang pengembangan sumber daya manusia dan penelitian di bidang perkeretaapian. Kerja sama ini dilakukan dalam rangka mempersiapkan SDM terkait pengoperasian dan pemeliharaan Kereta Cepat Jakarta-Bandung. Pada media massa tersebut tidak menyebutkan mengenai kerjasama terkait persiapan SDM dalam hal perencanaan teknis kereta cepat (Pratama, 2019).

Indonesia telah memiliki peraturan terkait perencanaan teknis kereta api, salah satunya adalah PM No. 60 Tahun 2012 tentang Persyaratan Teknis Jalur Kereta Api. Namun dalam peraturan ini belum memiliki standar yang sesuai dengan spesifikasi kereta cepat, yaitu kereta dengan lebar jalan rel $1435 \mathrm{~mm}$ dan kecepatan maksimum $350 \mathrm{~km} / \mathrm{jam}$. Sebelumnya telah ada penelitian mengenai geometri kereta api konvensional oleh Hubarat (2017), redesain geometri kereta api konvensional menggunakan PM No. 60 Tahun 2012. Hodas (2014) meneliti geometri kereta cepat di Slovakia. Slovakia menggunakan kereta cepat dengan kecepatan 260-300 km/jam, berbeda dengan penelitian ini, CR400AF Fuxing Train memiliki kecepatan 300-350 $\mathrm{km} / \mathrm{jam}$. Penelitian serupa lainnya adalah Kajian Peraturan Perencanaan Geometri Kereta Api (Kurniawan dan Triana, 2016), namun belum terdapat bahasan mengenai kereta cepat. Untuk saat ini telah ada PM No. 69 Tahun 2019 tentang Standar Spesifikasi Teknis Kereta Api Kecepatan Tinggi. Peraturan menteri ini mengatur beberapa hal seperti, jenis kereta api kecepatan tinggi, persyaratan umum, persyaratan teknis, dan persetujuan spesifikasi teknis, namun belum tercantum secara jelas mengenai geometri kereta kecepatan tinggi. Rencana pembangunana kereta cepat Jakarta-Bandung menggunakan kategori trek khusus tanpa pengembangan dari trek yang telah ada, terbukti dengan dilakukannya pembebasan lahan di sepanjang pembangunan HSRJB (Budisusilo, 2019).

Dilihat dari sudut pandang Prinsip Manajemen Infrastruktur, Rel Kereta Cepat ini harus dirancang dengan baik agar Rel terbangun bisa berfungsi dengan baik (Suprayitno \& Soemitro, 2018). Untuk itu beberapa hal terkait Aspek Rancang Bangun Geometri Rel harus diperiksa kebenaranya. Dalam hal ini terutama tentang Rancang Bangun Lengkung Horisontal.

Oleh karena itu Standar Perencangan Geometri Kereta Cepat perlu untuk dipikirkan. Makalah ini mebahas pemikiran tentang Standar Perancangan Geometri Lengkung Kereta Cepat.

\section{METODE PENELITIAN}

Metode penelitian yang digunakan adalah studi literatur dan pengumpulan data lapangan. Studi literatur dilakukan guna mendapatkan persamaan yang sesuai untuk penyelesaian geometri kereta cepat, dan data lapangan yang dikumpulkan untuk memenuhi persamaan tersebut. Geometi kereta cepat yang akan ditentukan adalah jari-jari lengkung horizontal dan peninggian rel. Adapun persamaan yang digunakan adalah sebagai berikut : 


\section{Lengkung Horizontal}

Lengkung horizontal adalah lengkung penghubung antara dua lintas lurus yang perpanjangannya bertemu dan membentuk sebuah sudut. Pada saat kereta api berjalan melalui lengkung horizontal, maka timbul gaya sentrifugal kea rah luar yang akan mengakibatkan (Utomo, 2013):

a. Rel luar mendapatkan tekanan yang lebih besar dibandingkan dengan rel bagian dalam.

b. Keausan rel luar akan lebih banyak dibandingkan rel bagian dalam.

c. Bahaya tergulingnya kereta api.

Untuk berbagai kecepatan rencana, besar jari-jari minimum yang diizinkan ditinjau dari 3 kondisi, yaitu: (Rosyidi, 2015)

Gaya Sentrifugal Diimbangi Sepenuhnya oleh Gaya Berat

Dapat dilihat pada Gambar 1. gaya-gaya yang bekerja saat kereta berada di tikungan. Gaya-gaya yang berlawanan harus bernilai sama besar agar terjadi keseimbangan. Berdasarkan persamaan dasar berikut:

$$
\begin{aligned}
& C=\frac{m \cdot V^{2}}{R} \\
& \begin{aligned}
\text { Dimana } & \\
\mathrm{m} & =\text { massa (ton) } \\
\mathrm{V} & =\text { kecepatan } \operatorname{kereta}(\mathrm{km} / \mathrm{jam}) \\
\mathrm{R} & =\text { jari-jari lengkung horizontal }(\mathrm{m})
\end{aligned} \\
& \text { (Sumber: Esveld, 2001) }
\end{aligned}
$$

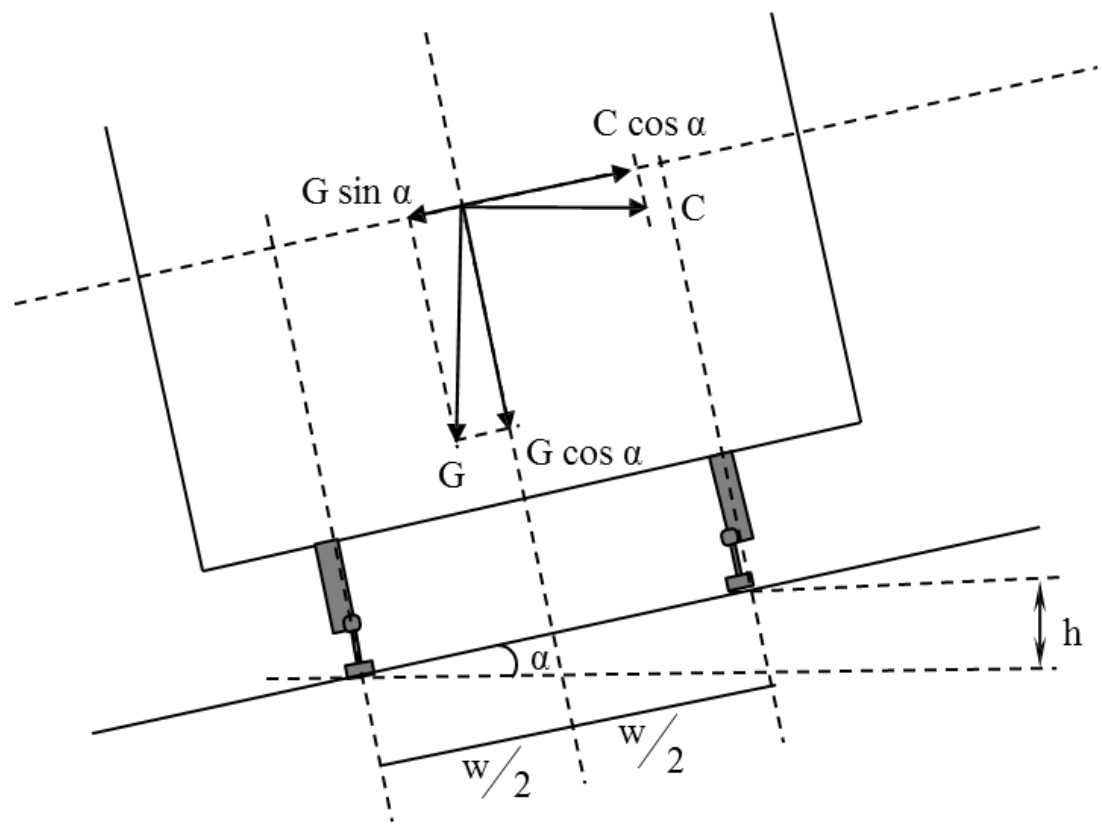

(Sumber : Rosyidi, 2015)

Gambar 1. Skematik gaya pada kondisi gaya sentrifugal hanya diimbangi oleh gaya berat.

Didapatkan gaya sentrifugal yang diimbangi oleh gaya berat sebagai berikut:

$$
\begin{aligned}
& h=\frac{w \cdot V^{2}}{g \cdot R} \\
& \text { (Sumber: Esveld, 2001) }
\end{aligned}
$$

Jika penggunaan lebar rel pada kereta cepat direncanakan $1435 \mathrm{~mm}$, maka jarak antara kedua titik kontak roda dan rel adalah 1500 mm (Esveld, 2001), sehingga dihasilkan persamaan: 


$$
R=\frac{11,8 \cdot V^{2}}{h}
$$

Dimana

$$
\begin{aligned}
& \mathrm{w} \quad=\text { jarak antar kontak rel }(\mathrm{mm}) \\
& \mathrm{g} \quad=\text { gaya gravitasi }\left(\mathrm{m} / \mathrm{s}^{2}\right) \\
& \mathrm{h} \quad=\text { peninggian } \operatorname{rel}(\mathrm{mm}) \\
& (\text { Sumber : Esveld, 2001) }
\end{aligned}
$$

\section{Gaya Sentrifugal Diimbangi oleh Gaya Berat dan Kemampuan Dukung Struktur Rel}

Komponen dukung komponen struktur jalan rel yang dimaksud adalah kemampuan dukung total yang dapat diberikan oleh komponen struktur jalan rel, yaitu rel, sambungan rel, penambat rel, bantalan dan balas. Dapat dilihat pada Gambar 2 untuk gaya-gaya yang bekerja.

$$
\begin{aligned}
& a=\left[\frac{V^{2}}{R}-g \frac{h}{w}\right] \\
& \text { (Sumber : Utomo, 2013) }
\end{aligned}
$$

dimana a percepatan sentrifugal $\left(\mathrm{m} / \mathrm{s}^{2}\right)$, karena $\mathrm{V}$ dalam satuan $\mathrm{km} / \mathrm{jam}$, maka perlu diubah menjadi $\mathrm{m} /$ det agar sesuai dengan a. Sehingga didapat persamaan:

$$
\begin{aligned}
& 13 R=\frac{V^{2}}{a+g \frac{h}{w}} \\
& \text { (Sumber: Utomo, 2013) }
\end{aligned}
$$

Agar penumpang tetap merasa nyaman, besarnya percepatan sentrifugal maksimum yang digunakan adalah 0,0478.g (Utomo, 2013), sehingga:

$$
\begin{aligned}
& 13 R=\frac{V^{2}}{0,0478 g+g \frac{110}{1200}} \\
& R=0,064 V^{2}
\end{aligned}
$$

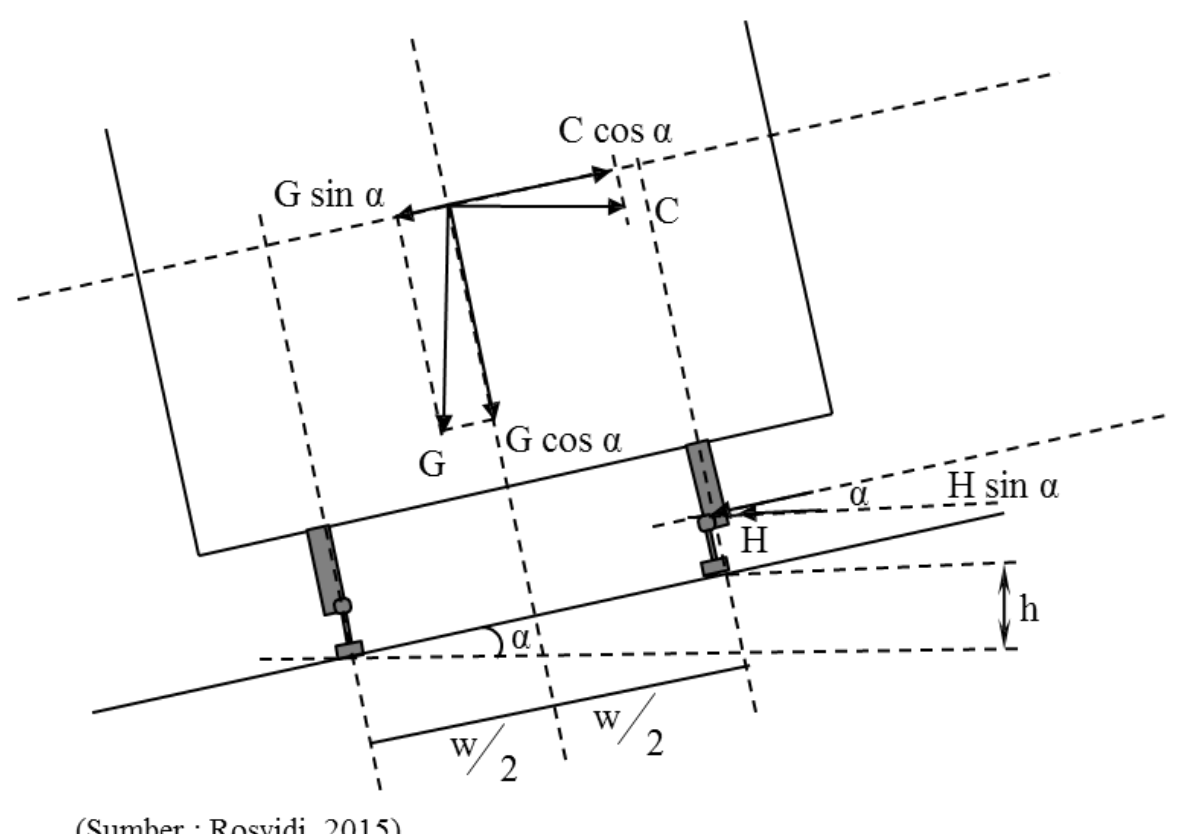

(Sumber : Rosyidi, 2015)

Gambar 2. Skematik gaya pada kondisi gaya sentrifugal hanya diimbangi oleh gaya berat dan daya dukung komponen rel 
Jari-jari Lengkung Tanpa Peninggian Rel

Pada lengkung horizontal tanpa adanya lengkung transisi dan tidak ada peninggian rel yang harus dicapai $(\mathrm{h}=0)$ maka:

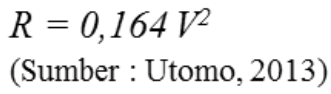

\section{Lengkung Transisi}

Lengkung transisi ditetapkan untuk mengeliminasi perubahan gaya sentrifugal sedemikian rupa sehingga penumpang di dalam kereta terjamin kenyaman dan keamanannya. Panjang lengkung peralihan merupakan fungsi dari perubahan gaya sentrifugal per satuan waktu, kecepatan dan jari-jari lengkung. Namun untuk kereta cepat dengan kecepatan V $=300$ $\mathrm{km} / \mathrm{jam}$ tidak memerlukan lengkung transisi (Rosyidi, 2015).

\section{Peninggian Rel}

Peninggian rel diperlukan untuk mengimbangi timbulnya gaya sentrifugal pada kereta saat memasuki suatu lengkung horizontal atau tikungan. Gaya sentrifugal tersebut mengakibatkan kereta cenderung terlempar ke luar dari lengkung, dan berbanding terbalik dengan jari-jari lengkung horizontal. Peninggian rel adalah salah satu cara agar dapat mereduksi gaya sentrifugal yang membebani kereta tersebut. Diterapkan pada rel bagian luar secara relatif terhadap rel bagian dalam di sepanjang lengkung horizontal (Rosyidi, 2015). Terdapat tiga peninggian rel, yaitu:

\section{Peninggian Rel Minimum}

Peninggian minimum didasarkan pada gaya maksimum yang mampu ditahan oleh komponen jalan rel dan kenyamanan bagi penumpang, dengan persamaan:

$$
h=\left[\frac{w \cdot V^{2}}{g \cdot R}-\frac{w \cdot a}{g}\right]
$$

(Sumber : Utomo, 2013)

\section{Peninggian Rel Normal}

Peninggian normal didasarkan pada kondisi jalan rel tidak menahan gaya sentrifugal. Pada kondisi ini gaya sentrifugal sepenuhnya diimbangi oleh gaya berat saja. Dengan persamaan sebagai berikut:

$$
\begin{aligned}
& R=0,054 V^{2} \\
& V=4,3 \sqrt{R}
\end{aligned}
$$

Apabila persamaan tentang hubungan antara $\mathrm{h}$ dengan $\mathrm{V}$ dan $\mathrm{R}$ di atas diwujudkan dalam bentuk:

$$
\begin{aligned}
& h=k \frac{V^{2}}{R} \\
& \text { (Sumber: Utomo, 2013) } \\
& \text { dengan } h_{\text {maks }}=150 \mathrm{~mm} \text {, maka: } \\
& h=k \frac{(4,3 \sqrt{ })^{2}}{R} \\
& \text { diperoleh nilai } \mathrm{k}=5,95, \text { maka persamaan peninggian normal adalah: } \\
& h_{\text {norma }} l=5,95 \frac{V^{2}}{R}
\end{aligned}
$$

\section{Peninggian Rel Maksimum}

Peninggian maksimum berdasarkan stabilitas kereta pada saat berhenti di bagian lengkung, digunakan faktor keamanan (safety factor, SF). Gambar 3 menunjukkan penurunan peninggian maksimum yang merupakan faktor keamanan terhadap gaya guling. 


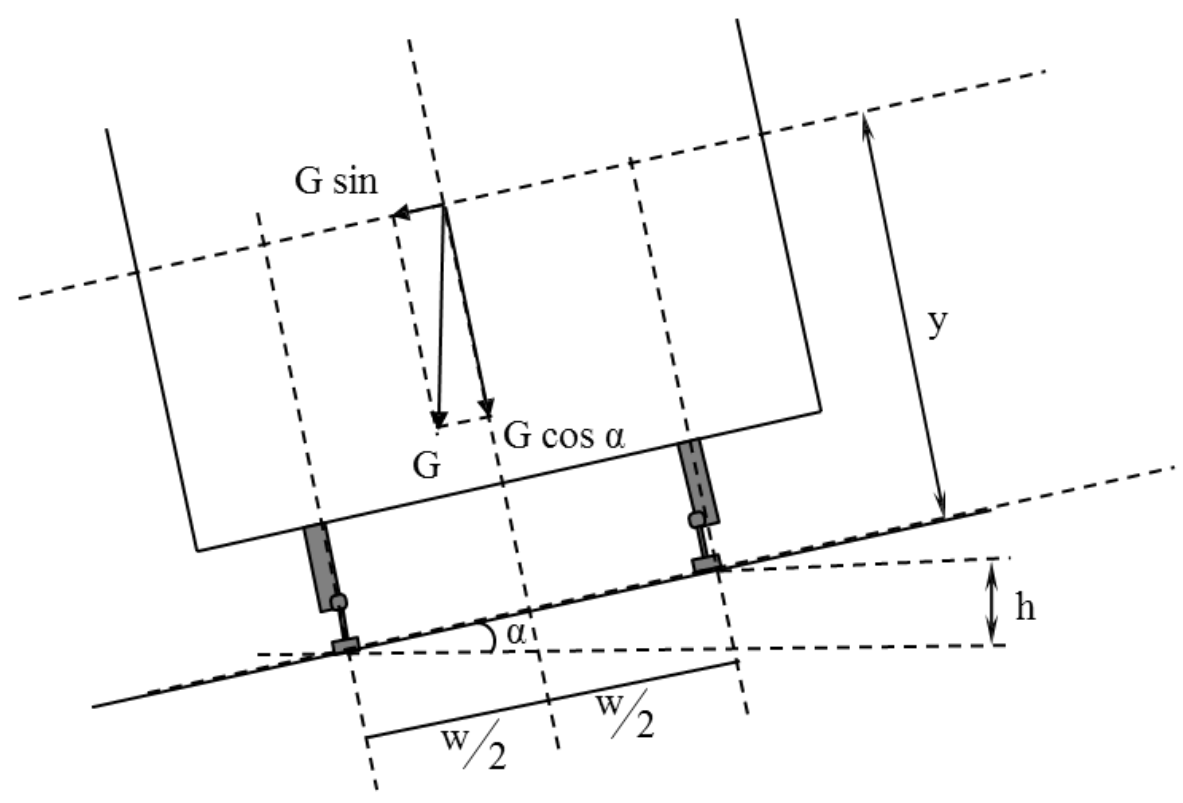

(Sumber : Rosyidi, 2015)

Gambar 3. Sistematik pengaruh peninggian maksimum yang merupakan faktor keamanan terhadap gaya guling

Ditinjau seluruh momen gaya berat terhadap titik 0 (di dasar rel bagian dalam) :

$$
\begin{aligned}
& S F \cdot G \sin \alpha \cdot y=G \cos \alpha \cdot \frac{w}{2} \\
& \tan \alpha=\frac{w}{S F \cdot 2 \cdot y}, \text { dan } \tan \alpha=\frac{V^{2}}{g \cdot R} \\
& \frac{h}{w}=\frac{w}{h m a k s \cdot 2 \cdot y} \\
& S F=\frac{w^{2}}{h m a k s \cdot 2 \cdot y} \\
& \text { Dimana } \\
& \quad \mathrm{w}=\text { jarak antar kontak rel (mm) } \\
& \quad \mathrm{h}_{\text {maks }}=\text { peninggian rel (mm) } \\
& \mathrm{y} \quad=\text { jarak antar titik berat dengan titik } 0(\mathrm{~mm}) \\
& \text { (Sumber: Utomo, 2013) }
\end{aligned}
$$

Dari ketiga peninggian tersebut harus memenuhi syarat berikut:

$$
\underset{\text { (Sumber : Utomo, 2013) }}{\mathrm{h}_{\text {minimum }}<\mathrm{h}_{\text {normal }}<\mathrm{h}_{\text {maksimum }}}
$$

Untuk memenuhi persamaan tersebut dibutuhkan beberapa data sekunder. Data-data tersebut berupa:

\section{Karakteristik Kereta CR400AF Fuxing Train}

Terdapat persamaan yang memerlukan data karakteristik kereta CR400AF Fuxing Train. Karakteristik kereta cepat yang perlu diketahui guna memenuhi persamaan tersebut adalah jarak titik berat kereta. Jarak ini dihitung dari titik 0 hingga ke titik berat kereta. Masing-masing kereta akan memiliki nilai titik berat yang berbeda walaupun masih dalam satu rangkaian.

\section{Standar Geometri Kereta Cepat di China}

Standar ini digunakan untuk membandingkan antara hasil yang didapatkan dari persamaan dengan standar itu sendiri dan sebagai pedoman dalam perencanaan kereta cepat Indonesia. 


\section{ANALISIS PENELITIAN}

Analisis geometri difokuskan pada alinyemen horizontal yaitu jari-jari lengkung dan peninggian rel kereta cepat. Dari hasil pengumpulan data dan studi literatur didapatkan data perencanaan kereta cepat Jakarta-Bandung yang ditunjukan pada Tabel 1.

Tabel 1. Data Perencanaan Kereta Cepat Jakarta-Bandung

\begin{tabular}{|l|l|}
\hline Kecepatan Rata-Rata & $300 \mathrm{~km} / \mathrm{jam}$ \\
\hline Kecepatan Maksimum & $350 \mathrm{~km} / \mathrm{jam}$ \\
\hline Lebar Rel & $1435 \mathrm{~mm}$ \\
\hline Jarak Titik Kontak Roda & $1500 \mathrm{~mm}$ \\
\hline Beban Gandar & 17 Ton \\
\hline \multicolumn{2}{|l}{ (Sumber: Technological Scheme, 2018) }
\end{tabular}

\section{Jari-jari Lengkung}

Besarnya jari-jari lengkung dipengaruhi oleh kecepatan rencana. Semakin tinggi kecepatan rencana maka semakin besar jari-jari lengkung yang dibutuhkan agar kereta tidak tergelincir saat melewati tikungan. Menentukan jari-jari lengkung sesuai kecepatan rencana dapat menghasilkan perencanaan yang lebih efisien dan ekonomis karena pada dasarnya jarijari lengkung dapat direncanakan sebesar apapun demi keamanan dan kenyamanan, namun tidak bernilai ekonomis.

Gaya Sentrifugal Diimbangi Sepenuhnya oleh Gaya Berat

Besar jari-jari lengkung horizontal dapat ditentukan dengan kondisi gaya sentrifugal diimbangi sepenuhnya oleh gaya berat. Kondisi ini disederhakan seperti pada Persamaan 3 . Hasil perhitungan untuk mendapatkan nilai jari-jari lengkung dapat dilihat pada Tabel 2.

Tabel 2. Jari-jari Lengkung Horizontal oleh Gaya Sentrifugal Diimbangi Oleh Gaya Berat

\begin{tabular}{|c|c|c|}
\hline Kecepatan (km/jam) & Peninggian Rel (mm) & Jari-Jari Lengkung (m) \\
\hline 300 & 150 & 7080 \\
\hline 350 & 150 & 9636,67 \\
\hline
\end{tabular}

Terdapat dua data kecepatan yaitu kecepatan rencana sebesar $300 \mathrm{~km} / \mathrm{jam}$ dan kecepatan maksimal $350 \mathrm{~km} / \mathrm{jam}$. Kedua kecepatan tersebut menggunakan peninggian rel maksimum yaitu 150 mm (PM No. 60 Tahun 2012). Kereta dengan kecepatan 300 km/jam membutuhkan jari-jari lengkung sebesar $7080 \mathrm{~m}$ atau $7,08 \mathrm{~km}$, dan kereta dengan kecepatan $350 \mathrm{~km} / \mathrm{jam}$ membutuhkan jari-jari lengkung sebesar 9636,67 $\mathrm{m}$ atau 9,637 km.

\section{Gaya Sentrifugal Diimbangi oleh Gaya Berat dan Kemampuan Dukung Struktur Rel}

Kondisi ini disederhanakan ke dalam bentuk Persamaan 6. Persamaan tersebut menggunakan lebar rel $1067 \mathrm{~mm}$, kemudian persamaan dimodifikasi sesuai kebutuhan lebar rel kereta cepat yaitu $1435 \mathrm{~mm}$. Untuk peninggian maksimum digunakan $150 \mathrm{~mm}$, sehingga didapatkan persamaan baru sebagai berikut:

$$
\begin{aligned}
& 13 \mathrm{R}=\frac{V^{2}}{0,0478 g+g \frac{150}{1500}} \\
& \mathrm{R}=0,053 \mathrm{~V}^{2}
\end{aligned}
$$

Dengan menggunakan Persamaan 11. dapat ditentukan jari-jari lengkung horizontal untuk masing-masing kecepatan kereta. Pada kondisi ini, kecepatan kereta 300 km/jam membutuhkan jari-jari lengkung sebesar $4770 \mathrm{~m}$ atau $4,77 \mathrm{~km}$, dan kecepatan saat kecepatan maksimum kereta $350 \mathrm{~km} / \mathrm{jam}$ membutuhkan jari-jari lengkung sebesar $6492,5 \mathrm{~m}$ atau $6,492 \mathrm{~km}$, dapat dilihat pada Tabel 3. 
Tabel 3. Jari-Jari Lengkung Horizontal oleh Gaya Sentrifugal Diimbangi Oleh Gaya Berat Kemampuan Dukung Komponen Struktur Jalan Rel

\begin{tabular}{|c|c|}
\hline Kecepatan (km/jam) & Jari-Jari Lengkung (m) \\
\hline 300 & 4770 \\
\hline 350 & 6492,5 \\
\hline
\end{tabular}

Jari-jari Lengkung Tanpa Peninggian Rel

Jari-jari lengkung tanpa peninggian rel yang dimaksud adalah tidak adanya kemiringan pada saat melewati tikungan atau $h=0$. Kondisi ini disederhanakan ke dalam Persamaan 7 . Persamaan tersebut menggunakan lebar rel $1067 \mathrm{~mm}$ sehingga perlu adanya modifikasi rumus agar sesuai dengan kebutuhan lebar rel yaitu $1435 \mathrm{~mm}$.

$$
\begin{aligned}
h & =\left[\frac{w \cdot V^{2}}{g \cdot R}-\frac{w \cdot a}{g}\right] \\
0 & =\left[\frac{11,8 \cdot V^{2}}{R}-71,7\right] \\
R & =0,165 V^{2}
\end{aligned}
$$

Dengan menggunakan Persamaan 12 dapat diketahui besar jari-jari lengkung yang dibutuhkan untuk kondisi tanpa peninggian rel. Dapat dilihat pada Tabel 4, pada saat kecepatan kereta $300 \mathrm{~km} / \mathrm{jam}$ jari-jari lengkung yang dibutuhkan adalah $14.850 \mathrm{~m}$ atau $14,85 \mathrm{~km}$, dan pada saat kecepatan maksimum yaitu $350 \mathrm{~km} / \mathrm{jam}$ didapat jari-jari lengkung sebesar $20.213 \mathrm{~m}$ atau $20,213 \mathrm{~km}$.

Tabel 4. Jari-Jari Lengkung Tanpa Peninggian Rel

\begin{tabular}{|c|c|}
\hline Kecepatan $(\mathbf{k m} / \mathbf{j a m})$ & Jari-Jari Lengkung (m) \\
\hline 300 & 14.850. \\
\hline 350 & $20.212,5$ \\
\hline
\end{tabular}

Terdapat perbedaan dari hasil perhitungan jari-jari lengkung pada masing-masing kondisi. Dapat dilihat pada Tabel 5 bahwa jari-jari lengkung terbesar diperoleh pada kondisi 3 yaitu tanpa peninggian rel sebesar 14,85 km pada kecepatan rencana dan 20,21 km pada kecepatan maksimum. Hal ini karena tanpa adanya peninggian rel saat di tikungan, jari-jari lengkung harus bernilai lebih besar atau hampir lurus agar terhindar dari bahaya tergelincir saat melewati tikungan dengan kecepatan yang telah direncanakan. Sedangkan jari-jari lengkung terkecil diperoleh pada kondisi kedua yaitu saat gaya sentrifugal diimbangi oleh gaya berat dan kemampuan komponen struktur jalan rel sebesar 4,77 km pada kecepatan rencana dan $6,49 \mathrm{~km}$ pada kecepatan maksimum. Berbeda dengan kondisi pertama yaitu gaya sentrifugal hanya diimbangi oleh gaya berat, kondisi kedua lebih kompleks yaitu gaya sentrifugal juga dipengaruhi oleh kemampuan komponen struktur jalan rel dimana adanya tambahan gaya horizontal yang melawan gaya sentrifugal saat kereta melewati tikungan. Hal tersebut yang membuat besar jari-jari lengkung yang didapatkan pada kondisi ini lebih kecil. Dari ketiga kondisi tersebut dapat dilihat bahwa semakin besar kecepatan nilai jari-jari lengkung juga semakin besar.

Tabel 5. Jari-Jari Lengkung Untuk Masing-masing Kondisi

\begin{tabular}{|c|c|c|c|}
\hline \multirow{2}{*}{$\begin{array}{c}\text { Kecepatan } \\
(\mathbf{k m} / \mathbf{j a m})\end{array}$} & \multicolumn{3}{|c|}{ Jari-Jari Lengkung (m) } \\
\cline { 2 - 4 } & Kondisi 1 & Kondisi 2 & Kondisi 3 \\
\hline 300 & 7080 & 4770 & 14850 \\
\hline 350 & 9636,67 & 6492,5 & 20212,5 \\
\hline
\end{tabular}




\section{Peninggian Rel}

Peninggian rel erat kaitannya dengan perencanaan jari-jari lengkung. Peninggian rel berguna agar pada saat kereta melewati tikungan tidak terlempar keluar jalur rel. Peninggian rel dibagi menjadi tiga, yaitu peninggian minimum, peninggian normal, dan peninggian maksimum.

\section{Peninggian Rel Minimum}

Peninggian rel minimum dihitung dengan menggunakan Persamaan 8. Dengan menggunakan nilai $\mathrm{w}$ (jarak antara kedua titik kontak antara roda dengan kepala rel) sebesar $1500 \mathrm{~mm}$, nilai percepatan sentrifugal a sebesar $0,1478 \mathrm{~m} / \mathrm{s}^{2}$, dan nilai gravitasi g sebesar 9,8 $\mathrm{m} / \mathrm{s}^{2}$, kemudian didapatkan persamaan baru yaitu:

$$
\mathrm{h}=\left[\frac{11,8 \cdot V^{2}}{R}-71,7\right]
$$

Dalam perhitungan peninggian rel minimum digunakan kecepatan kereta terbesar $\left(\mathrm{V}_{\text {maks }}\right)$. Kecepatan maksimum yang digunakan adalah $350 \mathrm{~km} / \mathrm{jam}$. Berdasarkan penentuan jari-jari lengkung, terdapat dua kondisi yang menggunakan peninggian rel, dari kedua kondisi tersebut kemudian ditentukan peninggian rel minimum masing-masingnya (Rosyidi, 2015). Dari hasil perhitungan menggunakan Persamaan 13, didapatkan besar peninggian rel minimum pada kondisi 1 adalah 78,3 mm, dan peninggian rel minimum pada kondisi 2 adalah 150,9 mm. Hasil perhitungan peninggian rel minimum untuk kereta cepat ditampilkan pada Tabel 6.

Tabel 6. Peninggian Rel Minimum

\begin{tabular}{|c|c|c|}
\hline Kondisi & Jari-Jari Lengkung (m) & Peninggian Rel (mm) \\
\hline 1 & 9636,67 & 78,3 \\
\hline 2 & 6492,5 & 150,9 \\
\hline
\end{tabular}

\section{Peninggian Rel Normal}

Peninggian rel normal telah disederhanakan dalam Persamaan 9. Pada persamaan tersebut menggunakan nilai hmaks $=110 \mathrm{~mm}$, kemudian dilakukan modifikasi persamaan agar sesuai dengan kebutuhan kereta cepat yaitu hmaks $=150 \mathrm{~mm}$, sehingga didapatkan persamaan baru sebagai berikut:

$$
\mathrm{h}=\mathrm{k} \frac{(4,3 \sqrt{ } R)^{2}}{R}
$$

Untuk mendapatkan nilai $\mathrm{k}$, pada Persamaan 5.4 dimasukan nilai hmaks $=150 \mathrm{~mm}$, diperoleh nilai $\mathrm{k}=8,11$, maka persamaan untuk peninggian normal kereta cepat adalah:

$$
\mathrm{h}_{\text {norma }} \mathrm{l}=8,11 \frac{V^{2}}{R}
$$

Sama dengan menghitung peninggian minimum, menghitung peninggian normal juga dilakukan pada dua kondisi jari-jari lengkung. Pada kondisi pertama, dengan besar jari-jari lengkung 7,08 km didapatkan nilai peninggian normal rel sebesar 103,09 mm, sedangkan pada kondisi kedua dimana nilai jari-jari lengkungnya lebih kecil yaitu 4,77 km didapatkan nilai peninggian normal rel sebesar $153,07 \mathrm{~mm}$. Hasil perhitungan peninggian normal rel ditampilkan pada Tabel 7 .

Tabel 7. Peninggian Rel Normal

\begin{tabular}{|c|c|c|}
\hline Kondisi & Jari-Jari Lengkung (m) & Peninggian Rel (mm) \\
\hline 1 & 7080 & 103,09 \\
\hline 2 & 4770 & 153,07 \\
\hline
\end{tabular}




\section{Peninggian Rel Maksimum}

Berdasarkan Persamaan 10, perhitungan peninggian rel maksimum mempertimbangkan safety factor agar kereta tetap stabil saat berhenti di bagian lengkung. Menghitung besarnya peninggian maksimum rel diperlukan variabel lain yaitu jarak titik berat kereta terhadap titik nol. Dari data yang didapatkan jarak titik berat kereta cepat CR400AF fuxing train ditampilkan dalam Tabel 8.

Tabel 8. Jarak Titik Berat Kereta Terhadap Titik 0

\begin{tabular}{|c|c|c|c|c|c|c|c|c|}
\hline Sumbu & Car No.1 & Car No.2 & Car No.3 & Car No.4 & Car No.5 & Car No.6 & Car No.7 & Car No.8 \\
\hline X & $-0,08$ & 0,11 & 0,141 & 0,069 & 0,14 & $-0,141$ & $-0,11$ & 0,313 \\
\hline Y & $-0,007$ & 0,006 & 0,019 & 0,013 & 0,002 & $-0,019$ & $-0,006$ & 0,017 \\
\hline Z & 1,538 & 1,478 & 1,55 & 1,441 & 1,506 & 1,55 & 1,478 & 1,523 \\
\hline
\end{tabular}

(Sumber: JBHSR EMU Gravity Center Data)

Dari data jarak titik berat kereta diambil jarak titik berat terpendek yaitu pada Car No. 3 atau Car No. 6 sebesar 1,550 m atau $1550 \mathrm{~mm}$, sehingga didapatkan SF sebagai berikut:

$$
\begin{aligned}
& S F=\frac{w^{2}}{h \text { maks } \cdot 2 \cdot y} \\
& S F=\frac{1500^{2}}{150 \cdot 2 \cdot 1550} \\
& S F=4,8
\end{aligned}
$$

Safety Factor yang didapatkan dengan menggunakan h maks $=150 \mathrm{~mm}$ adalah 4,8 . Nilai ini sudah dapat dikategorikan aman dalam sebuah perencanaan. Jika menggunakan nilai jarak titik berat terpendek yaitu $1441 \mathrm{~mm}$, maka nilai SF yang didapat semakin besar yaitu 5,2. Nilai SF semakin besar apabila jarak titik berat semakin pendek. Menentukan peninggian rel maksimum dapat dilakukan dengan menentukan nilai SF terlebih dahulu. Persamaan yang digunakan adalah penurunan rumus dari persamaan sebelumnya, seperti yang ditunjukan pada persamaan berikut:

$$
\begin{aligned}
h & =\frac{w^{2}}{S F \cdot 2 \cdot y} \\
h & =\frac{1500^{2}}{5.2 \cdot 1550} \\
h & =145,16 \mathrm{~mm}
\end{aligned}
$$

Dengan nilai $\mathrm{SF}=5$, didapatkan peninggian rel maksimum yaitu $145,16 \mathrm{~mm}$. Persamaan 15 dapat menentukan peninggian rel maksimum berapapun sesuai SF yang diinginkan. Semakin besar angka SF yang diinginkan, semakin kecil nilai peninggian maksimum rel yang didapatkan. Rekap hasil perhitungan peninggian rel dapat dilihat pada Tabel 9.

Tabel 9. Hasil Perhitungan Peninggian Rel Kereta Cepat

\begin{tabular}{|c|c|c|c|}
\hline Kondisi & h minimum (mm) & h normal (mm) & h maksimum (mm) \\
\hline 1 & 78,3 & 103 & 145,16 \\
\hline 2 & 150,9 & 153,07 & 145,16 \\
\hline Syarat & \multicolumn{2}{|c|}{$\mathrm{h}$ minimum < h normal < h maksimum } \\
\hline
\end{tabular}

Pada kondisi 1 didapatkan nilai peninggian minimum sebesar 78,3 $\mathrm{mm}$ dimana nilai ini hampir dua kali lebih kecil dibandingkan peninggian minimum pada kondisi 2 yaitu 150,9 mm. Untuk perhitungan peninggian normal rel, pada kondisi 1 didapatkan hasil $103 \mathrm{~mm}$, sedangkan pada kondisi 2 didapatkan peninggian normal sebesar $153,07 \mathrm{~mm}$, nilai ini lebih besar dari peninggian rel maksimum yang disyaratkan pada PM No. 60 Tahun 2012 untuk kereta dengan lebar rel $1435 \mathrm{~mm}$ yaitu $150 \mathrm{~mm}$. Sedangkan untuk peninggian maksimum rel dihitung berdasarkan nilai SF dan jarak titik berat kereta, sehingga baik pada kondisi 1 maupun 2 hasilnya sama yaitu 145,16 mm. Dari hasil perhitungan kedua kondisi tersebut, peninggian rel 
yang memenuhi syarat adalah pada kondisi 1 yaitu nilai peninggian minimum < peninggian normal < peninggian maksimum. Sedangkan hasil perhitungan peninggian rel menggunakan kondisi 2 tidak memenuhi syarat. Hal ini dikarenakan nilai jari-jari lengkung yang terlalu kecil sehingga membutuhkan peninggian rel yang lebih besar. Salah satu cara agar kondisi 2 dapat memenuhi syarat adalah dengan menurunkan nilai SF, namun pada perencanaan kereta cepat memang diharapkan tingkat keamanan yang lebih tinggi dibandingkan dengan perencanaan kereta biasa, karena semakin tinggi kecepatan suatu moda transportasi maka semakin tinggi fatalitas saat terjadi kecelakaan.

Dari hasil analisis jari-jari lengkung kereta cepat didapatkan tiga nilai berbeda pada masing-masing kondisinya. Nilai-nilai tersebut dibandingkan dengan standar geometri yang telah diberlakukan di China. Standar jari-jari lengkung yang digunakan oleh China dapat dilihat pada Tabel 10.

Tabel 10. Standar Geometri Jari-jari Lengkung Kereta Cepat China

\begin{tabular}{|l|l|l|c|c|c|}
\hline \multicolumn{3}{|c|}{ Design speed $(\boldsymbol{k m} / \mathbf{h})$} & $\mathbf{3 5 0}$ & $\mathbf{3 0 0}$ & $\mathbf{2 5 0}$ \\
\hline \multirow{4}{*}{ Minimum value $(\boldsymbol{m})$} & \multirow{2}{*}{ Ballasted track } & Normal condition & 7000 & 5000 & 3500 \\
\cline { 2 - 5 } & \multirow{2}{*}{ Ballastless track } & Difficult condition & 6000 & 4500 & 3000 \\
\cline { 3 - 6 } & Normal condition & 7000 & 5000 & 3200 \\
\hline & Difficult condition & 5000 & 4000 & 2800 \\
\hline
\end{tabular}

(Sumber: TB 10621-2014, 2014)

China menetapkan standar minimum jari-jari lengkung untuk kondisi normal yang menggunakan balastless track adalah $5000 \mathrm{~m}$ dan jari-jari lengkung maksimum adalah 12000 $\mathrm{m}$. Hasil analisis yang memenuhi standar ini adalah jari-jari lengkung pada kondisi satu, yaitu jari-jari lengkung dengan nilai minimum $7080 \mathrm{~m}$, untuk dua kondisi lainnya tidak memenuhi standar yang ditetapkan oleh China.

\section{KESIMPULAN}

Hasil analisis yang didapatkan kemudian dibandingkan dengan standar geometri yang berlaku di China. Hasil perbandingan menghasilkan kesimpulan sebagai berikut.

1. Perhitungan jari-jari lengkung dibagi menjadi tiga kondisi, kondisi pertama didapatkan nilai $7080 \mathrm{~m}$, kondisi kedua adalah $4770 \mathrm{~m}$, dan kondisi ketiga adalah $14850 \mathrm{~m}$.

2. Jari-jari lengkung minimum yang memenuhi standar perencanaan kereta cepat China adalah jari-jari lengkung minimum pada kondisi pertama, yaitu $7080 \mathrm{~m}$.

3. Peninggian rel yang didapatkan menggunakan rumus yang telah disesuaikan dengan karakteristik kereta cepat CR400AF adalah, peninggian rel minimum sebesar 78,3 mm, peninggian normal sebesar 103,09 $\mathrm{mm}$, dan peninggian maksimum sebesar $150 \mathrm{~mm}$.

\section{REKOMENDASI}

Seperti yang tertera dalam PM No. 60 Tahun 2012, terdapat rumus yang dapat dijadikan acuan untuk geometri kereta api, sama hal nya dengan kereta cepat, rumus yang dapat direkomendasikan untuk dijadikan acuan dalam standar perencaan geometri kereta cepat adalah persamaan yang digunakan dalam menghitung jari-jari lengkung dengan kondisi gaya sentrifugal diimbangi sepenuhnya oleh gaya berat. Sedangkan untuk standar peninggian rel, masih dapat menggunakan standar yang ditetapkan oleh PM No. 60 Tahun 2012 yaitu $150 \mathrm{~mm}$ untuk kereta dengan lebar rel $1435 \mathrm{~mm}$.

Perlu adanya penelitian lebih lanjut untuk melengkapi standar geometri kereta cepat, seperti penetapan standar maksimum jari-jari lengkung, alinyemen vertikal dan lain-lain. Adanya saran untuk pemerintah agar dapat menyusun peraturan terkait standar perencanaan 
kereta cepat di Indonesia. Standar perencanaan kereta cepat Indonesia perlu dirancang sedemikian rupa sehingga Indonesia dapat memiliki transportasi masal modern yang berkesinambungan.

CATATAN. Penulis mengucapkan terima kasih kepada Bapak Suryo Hapsoro Tri Utomo dan Bapak Imam Muthohar selaku dosen pembimbing dalam penyusunan laporan ini, dan kepada PT. Wijaya Karya (Persero) Tbk yang telah membantu penulis dalam memperoleh data lapangan, serta pihak-pihak terkait.

\section{DAFTAR PUSTAKA}

Budisusilo, Arif. (2019). "Milestone Kereta Cepat Jakarta-Bandung”. Bisnis.com, Jumat 17 Mei 2019.

CSR Qingdao Sifang Co,. Ltd Document No. EPC-KCIC-CRRC-002A 2018 about Overall Technological Scheme.

Esveld, Coenraad (2001). Modern Railway Track. MRT-Productions. Netherlands.

Hodas, Stanislav. (2014). Design of Railway Track for Speed and High-speed Railways. Procedia Engineering. Slovak Republic.

Hutabarat, Kevin W. (2017). Implikasi Redesain Geometri Jalur Kereta Api (Studi Kasus: Jalur KA Pekanbaru-Muaro KM 01+000-10+000). Skripsi Sarjana. Program Studi Teknik Sipil Fakultas Teknik. Universitas Gadjah Mada.

Kurniawan, Hafidz H. \& Triana, Sofyan (2016). "Kajian Peraturan Perencanaan Geometri Jalan Kereta Api Indonesia". Proceedings of the 19th International Symposium of FSTPT Islamic University of Indonesia. Yogyakarta.

PerMen Hub. 60/12. Peraturan Menteri Perhubungan Nomor 60 Tahun 2012 tentang Persyaratan Teknis Jalur Kereta Api.

PerMen Hub. 69/19. Peraturan Menteri Perhubungan Nomor 69 Tahun 2019 tentang Standar Spesifikasi Teknis Kereta Api Berkecepatan Tinggi.

Pratama, Akhdi M. (2019). "Belajar Soal Kereta Cepat, Kemenhub Kirim Tim ke China". Kompas, Jumat 11 Oktober 2019.

Rosyidi, Sri A. P. (2015). Rekayasa Jalan Kereta Api. LP3M UMY. Yogyakarta.

Suprayitno, H. \& Soemitro, R.A.A. (2018). "Preliminary Reflexion on Basic Principle of Infrastructure Asset Management”. Jurnal Manajemen Aset Infrastruktur \& Fasilitas, 2(1) Maret 2018.

TB 10621-2014. Professional Standard of The People's Republic of China 2014 about Code for Design of High-speed Railway. China Railways Publishing House. Beijing.

Utomo, Suryo H. T. (2013). Jalan Rel. Beta Offset. Yogyakarta. 